fine nerve-fibres passing from the nerves of the cutis into the deeper layer of cuticular cells, and also star-and spindle-shaped cells in the cuticle, which, he suggests, may be nervous structures, though he has not traced them in connection with nerve-fibres. On the surface of young fishes and naked amphibia, F. E. Schultze has discerned nervehairs arranged in the form of tufts or brushes, very much as is the case in the organ of hearing. In this instance, the brush-like endings of the nerves are probably connected with touch.

Cohnheim has described the corneal nerves as forming a superficial plexus under the anterior elastic lamina; from these, perforating branches pass perpendicularly through the lamina, and then under the epithelium, and break up into brush-like or star-shaped finer branches, which form a plexus, giving off fine nerves at tolerably regular intervals, between the deep columnar cells and the more superficial spheroidal ones, and dividing at length into their finest branches, which end by somewhat swollen extremities in the most superficial epithelial layers. Thus the exquisite sensibility of the front of the eye, like that of the olfactory or the gustatory mucous membrane, may be accounted for.

When I look upon the vast amount of research which has been applied to this department of biology for some years past, and think that the instrument which has afforded the great means for it was only perfected, so as to be capable of use for such purposes, about 1820,1 cannot but congratulate the section on the abundant fruits we are reaping ; and when, in addition, I contemplate the amount of certainty which physical science has imparted to physiology, by furnishing the means of examining and accurately measuring the rates of transmission of nerve currents ; of obtaining tracings of the respiratory movements and of the arterial pulsations; of examining the retina in the living eye, and the larynx of a living man, almost as readily as if these parts were exposed in dissection, I cannot but conclude that this nineteenth century has been already distinguished as a very notable one for biology, and especially for physiology. Considering that so much time is required for making a single careful observation, it is very fortunate that so large an array of inquirers and so much talent are employed upon the subjects in which we are interested, and that once a year we have the admirable opportunity of listening to the results of inquiries instituted by the most eminent men in all parts of the world, and of hearing different views advocated with the greatest earnestness, and yet with perfect good humour, and a rigorous determination to rest satisfied with nothing but the truth.

\section{CASE OF DRY GANGRENE OF THE PENIS.*}

By CHAUNCY PUZEY, L.R.C.P., M.R.C.S., Honorary Surgeon to the Liverpool Royal Infirmary Lock Hospital.

THE subject of the following remarks is a man, aged 34, single, a smith, who, in 1869 , contracted a chancre, which was followed by a suppurating bubo and by sloughing of the whole prepuce, for which he was treated in hospital. Whether the sore which afterwards sloughed had been indurated, or whether he had, a short time previously, had an indurated sore, cannot be ascertained; but he appears to have had secondary symptoms early in 1870 . In September 1870 , he went out to India, where he remained until May 1873 . Whilst there, he was frequently laid up with attacks of intermittent fever, for which he treated himself with quinine.

He says that, from the year I870, he did not have sexual connection, until November last, when he did so whilst intoxicated. A day or so afterwards, he noticed a small red spot near the frenum, which ulcerated and became painful. The sore gradually increased, and caused him so much distress, that he came into the Lock Hospital in the middle of December.

He was then suffering from slow serpiginous ulceration, apparently of the cicatricial tissue, which had resulted from the sloughing of the prepuce in 1869. There was no deep sloughing, but the sore was dirty, apparently creeping along superficially, and throwing off flakes of sphacelated tissue ; it was covered with a fotid and acrid discharge. The whole surface was at once thoroughly swabbed with pure nitric acid, and afterwards dressed with strong opium lotion; opium, nitric acid, and cinchona with wine, and nourishing diet, formed the general treatment. The sore, however, crept on ; again acid was applied, and again another time the acid pernitrate of mercury. Various lotions were tried-mercurial, iron, and carbolic acid-but nothing caused the slightest improvement. The ulcer gradually involved the whole of the old cicatrix.

About the end of the second week of January, it was noticed that

* Read before the Liverpool Medical Institution the glans penis was wrinkled and apparently shrivelling ; in a few days more, it became dusky, and was evidently dead; and now it was apparent that the skin of the whole of the penis was becoming cold and dusky; then the penis itself became smaller, and, by the end of January, a good line of demarcation had formed at its junction with the scrotum, and it was manifest that the whole of the organ was dead. All the urine was passed through the meatus until the beginning of February, when the urethra became penetrated at the line of demarcation. Action here was very sluggish; lotions, containing 25 per cent. of compound tincture of benzoin, were now used, and, by the end of February, the penis was detached with the exception of a few fibres of tough mortified tissue, which were divided with scissors. No hæmorrhage occurred at any time. The detached organ was perfectly black, dry, and hard. The man left the hospital in March.

I have brought this case forward, because it appears to me to be interesting : Istly, on account of its rarity; and 2ndly, because it is peculiar from a pathological point of view.

First, with regard to its rarity. I have looked through a considerable number of the periodicals published for the last twenty years, and have only found two cases recorded at all resembling that which I have described. (These were cases brought before the notice of the Pathological Society, by the late Professor Partridge, on March 2 Ist, I865, and on February 7 th, 1870.) In the Archives Générales de Médecine for 1870 , there is a paper by M. Demarquay "On Gangrene of the Penis". He says that he has collected twenty-five cases from different journals; but I find that in this number he includes loss of the penis from sloughing phagedæna, from mechanical injuries, and all forms of moist gangrene ; and he acknowledges that dry gangrene of the whole penis is very rare, and must be generally allied to some predominant general condition depressing the whole system.

This leads me to the second point: What was the cause of the peculiar train of symptoms in this case? There can be no cloubt as to the form of gangrene which occurred. It was the slow, dry gangrene arising from the cutting off of the supply of blood to the affected part; and the question is, how this occurred. At first, it struck me that it might be due to syphilitic deposit in or around the arterial walls, gradually obliterating the channel of the vessels ; but, considering the number of vessels supplying the penis, it is difficult to suppose that all these vessels could be affected so simultaneously. It is quite possible that they might have undergone some degeneration which assisted in the result described; but we must look for something more than that. I am inclined to look upon it as a case nearly allied to, even if we cannot actuaily call it, senile gangrene. And here I would draw attention to the general appearance of the patient when he first came under my observation. He was very wasted, with a thin delicate skin, and sallow complexion. His circulation was very feeble; his nose frequently blue at the tip; his fingers exceedingly taper, and his hands delicate, like a woman's. He had several pustulo-crustaceous spots about different parts of the body; the cicatrix of an abscess in the groin, and several livid cicatrices about his legs, the result of abrasions; one, especially large, the result of an incised wound. His legs looked like those of an emaciated old man.

Sir James Paget, in his Pathology, says :- "Senile gangrene occurs often in those who are old in structure rather than in years; it affects tissues already degenerate. . . Some injury or disease, even a very trivial one, kills that which was already nearly dead. . . . The parts around or within it become inflamed, and in these (degenerate as they already were) the further degeneration of the inflammatory process is destructive."

"There are many cases in which explanation, except in the most general and vague terms is difficult. In some, the local death is to be attributed to defective quality of the blood. . . . Certain parts, even small and circumscribed parts, may die through defects or errors of the blood, which yet do not quite hinder it from maintaining the rest of the body."

Sir Benjamin Brodie, in his essay on Mortification, says that one of the worst cases of senile gangrene which he ever saw occurred, after a slight injury, in a man, 36 years of age, worn out by the operation of bad habits on a bad constitution. This man had been a soldier, and had served in India and Canada.

Billroth, in his Surgical Pathology", says :- "In acute (marasmic) gangrena senilis, the primary coagulation due to feeble circulation occurs in the capillaries, and thence extends backwards to the arteries."

"Very rare", he says, "are the cases where, from excessive anæmia, the arteries are so much contracted, that but little blood circulates through the smaller branches, and the nervous excitation of the heart is so slight, that its contractions are incomplete. . . The patients, who are generally young, often suffer from rigidity of the hands and feet, fainting fits, and fatigue." 
Billroth relates the following case. A young very anæmic man had, without any apparent cause, first, gangrene of the tip of the nose, then of both feet. After suffering for four months, he died; and, as in the patient, so in the dead subject, he could find nothing morbid beyond the excessive inexplicable anæmia.

My idea as to the pathology of the case which I have related is as follows. We evidently had to deal with a man originally of delicate frame; who had suffered from syphilitic infection; whose originally feeble constitution had been still further deteriorated by residence in a hot climate, and who had, according to his own account, suffered from repeated attacks of one of the climatic fevers. Under these circumstances, probably after an orgie, he has sexual connection, and suffers from a sore in consequence. This sore is situated on a part composed of feeble tissue, a cicatrix resulting from a sloughing sore; a low form of inflammation is set up, leading to progressive death of the surrounding superficial textures. This slow destructive action spreads round the penis, behind the corona glandis; then, either from inflammatory adhesion or plugging of the adjacent arterial branches, the glans dies. Up to this point, the rest of the penis has been unaffected; but now comes the effort of nature to throw off she dead portion, the inflammatory process in a deteriorated part (as described by Paget) takes place, which is too much for these feeble structures, and kills them; and so the mortification extends until the whole of the projecting part of the organ is destroyed.

[I have omitted to state that neither albumen nor sugar was found in the urine ; and, further, that no visceral mischief of any kind could be detected.]

\section{EXTRACTION OF A WATERLOO BULLET WHICH HAD REMAINED IMBEDDED IN THE PALM OF THE HAND FOR UPWARDS OF FIFTY-NINE YEARS.}

By HENRY HARLAND, M.D., Wadhurst, Sussex.

JAMES JENNER, aged 83 , fought at Waterloo, on June 18 th, 1815 , in the 44th Foot. In the thickest of the action, near Quatre Bras, whilst he was discharging his musket, a French bullet struck his forefinger. It passed through the proximal phalanx to the barrel of his musket, which it indented, and thence through the fleshy part of the ball of the thumb, down to the trapezium, against the palmar surface of which it became imbedded, and which probably arrested its further progress. Jenner immediately sought surgical aid ; the wound was probed several times, but, as the bullet could not be detected, no attempt at extraction was made; he was never afterwards fit for duty. The wound remained open two years, and then healed, leaving so much induration in the palm as to render it very difficult for him to grasp his agricultural tools, and quite impossible to close the hand.

I first became acquainted with the patient twenty-five years ago. $\mathrm{He}$ has constantly worked as a gardener or agricultural labourer since his discharge from the army in 1816 , excepting at those times when the hand has been unusually painful. About forty years ago, he was laid up three months, in consequence of irritation and lymphatic inflammation, induced by the bullet, and was frequently at other times incapacitated for several days at a time. About three months ago, when working on very hard ground, the hand became painful and swollen. An abscess formed and opened on the dorsal surface of the hand, midway between the metacarpo-phalangeal joints of the thumb and forefinger. I passed down a probe, and felt the bullet distinctly in the situation before-mentioned. After enlarging the opening sufficiently, I had very little difficulty in dislodging and extracting the bullet with the scoop. It was blackened, and slightly flattened on one side, probably from its first striking the barrel of the musket. The patient told me that the English at that time used the ounce and spherical bullets, but that the French bullets were smaller. This weighed six drachms and five grains. The wound is rapidly healing; but considerable time must elapse before it is completely closed, in consequence of the depth of the sinus, which is kept open by being filled with lint, soaked in dilutecarbolic acid.

The interest of the case consists in the fact of a leaden bullet remaining deeply imbedded upwards of fifty-nine years without producing more inconvenience. I think it highly probable that, during the patient's work on very hard ground, the bullet may have become dislodged from its long resting place, either by concussion of the tool against the ground, or by some pressure directly applied to the palm, and that the abscess resulted from its sudden and probably violent displacement.

\section{ON THE INDUCTION OF PREMATURE LABOUR.}

By WILLIAM DRAPER, M.R.C.S., etc., York.

Formerly Resident Obstetric Officer to the Middlesex Hospital.

THE question of Induction of Premature Labour, which has been recently brought forward in the BRITISH MEDICAL JOURNAL, must, I apprehend, be one of importance and interest to all obstetricians; and as I cannot quite agree, in every respect, with some of the views promulgated in a very carefully prepared paper on the subject, in the JOURNAL of August 8th, I would add some remarks relative to the operation.

In the paper referred to a most interesting digest, with statístics, is given of twenty cases in which premature labour was induced. Although the practice chiefly followed in these cases, that of dilating the os uteri with sponge-tents, may be, as is alleged by its advocate, safe, it is certainly a slow process ; and, according to my own experience, results at least as favourable, both to mother and child, are attainable by a more rapid and less irksome operation, such, for instance, as that advised by Dr. Barnes.

An analysis of the twenty cases given shows, I believe, that the average duration of time occupied for the completion of labour was rather over four days per case; the longest duration of time, by the tent process, being sixteen days, the shortest thirty-six hours. By the more expeditious plan of Dr. Barnes, we may, I think, with tolerable certainty, count upon the operation being terminated within twentyfour hours. A typical case in point, which recently occurred to me, is fresh in my memory.

Certain conditions of a patient necessitated labour being induced between the seventh and eighth months of gestation. In accordance with Dr. Barnes's practice, I introduced into the uterus overnight an elastic bougie, which I withdrew at my visit on the following morning, uterine action having then commenced. At an afternoon visit, I found that slight pains had continued during the day, and that the os (both external and internal) admitted the finger easily; I therefore introduced, without difficulty, a small-sized hydrostatic bag, and gradually dilated to its full extent ; the second and third sized bags were then successfully employed, and good dilation resulted. The membranes were next ruptured, the largest sized bag replaced, and the patient left until good expulsive pains came on, which occurred about three hours later; and although the labour was somewhat retarded by a footling presentation, it was terminated within twenty-two hours of the commencement of the operation. There was prolapsus of the funis in this case; and the child, being unusually small and weakly for seven-and-a-half months, survived its birth only for a short time. The mother made an uninterrupted recovery.

This case, I believe, is only a common illustration of general experience, both with respect to time and process, when a like method of procedure is adopted. With all due deference, therefore, to large experience, and to what has been otherwise said on the subject, I cannot dissuade myself from the opinion that, after premature labour has once been provoked, the sooner, within reasonable bounds, the uterus is emptied and the fotus liberated, the better will be the chance of saving the latter, and the more favourable will be the conditions of recovery for the mother, in curtailing the shock to the system and the strain upon her strength and patience.

\section{CLINICAL MEMORANDA.}

\section{MAMMARY ABSCESS IN INFANTS.}

Mr. JAMEs Robinson writes: A short time ago, I was requested to see an infant one month old, when I found it to be suffering from mammary abscess on the right side. There was no constitutional disturbance. The swelling was about the size of a walnut, inflamed, and quite distinctly fluctuating. I opened it with the ordinary bistoury, and ordered linseed-meal poultices. It rapidly healed. The swelling had been observed about ten or twelve days. The breast had not been at all manipulated by the nurse or any other person.

Mr. P. Downey (Sileby) says that in Drs. Evanson's and Maunsell's work on Diseases of Children, published in Dublin in I 847, at page $21 \mathbf{I}$, swelling of the breast and occasional abscess are mentioned as occurring in infants. At page 202, abscesses are noted as forming large collections of matter. Mr. Downey had a case in 1855 in an infant, in whom seven abscesses successively formed, and were opened when they pointed. The patient recovered, and she is now a strong girl. Another case was in a boy who had four formations of a similar kind, and is now a healthy boy. 